\title{
Flood risks in urbanized areas - multi-sensoral approaches using remotely sensed data for risk assessment
}

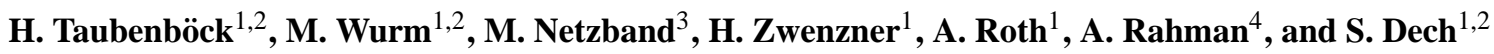 \\ ${ }^{1}$ German Remote Sensing Data Center (DFD), German Aerospace Center (DLR), 82234 Wessling, Germany \\ ${ }^{2}$ Julius-Maximilians-Universität Würzburg, Department of Geography, Am Hubland, 97074 Würzburg, Germany \\ ${ }^{3}$ Ruhr-Universität Bochum, Remote Sensing Group, Department of Geography, 44780 Bochum, Germany \\ ${ }^{4}$ Jamia Millia Islamia University, Faculty of Natural Sciences, Department of Geography, New Delhi-110025, India
}

Received: 3 May 2010 - Revised: 22 November 2010 - Accepted: 20 December 2010 - Published: 14 February 2011

\begin{abstract}
Estimating flood risks and managing disasters combines knowledge in climatology, meteorology, hydrology, hydraulic engineering, statistics, planning and geography - thus a complex multi-faceted problem. This study focuses on the capabilities of multi-source remote sensing data to support decision-making before, during and after a flood event. With our focus on urbanized areas, sample methods and applications show multi-scale products from the hazard and vulnerability perspective of the risk framework. From the hazard side, we present capabilities with which to assess flood-prone areas before an expected disaster. Then we map the spatial impact during or after a flood and finally, we analyze damage grades after a flood disaster. From the vulnerability side, we monitor urbanization over time on an urban footprint level, classify urban structures on an individual building level, assess building stability and quantify probably affected people. The results show a large database for sustainable development and for developing mitigation strategies, ad-hoc coordination of relief measures and organizing rehabilitation.
\end{abstract}

\section{Introduction}

The world has suffered from severe flooding over the last decennium. In recent years the huge impact of floods, which include river floods, flash floods, storm surge or tsunamis, has caused hundreds of thousands of deaths, destruction of infrastructure, disruption of economic activity and the loss of property worth billions of dollars. Prominent examples are floods due to heavy rainfall in Germany in 2002, the tsunami on the coasts of the Indian Ocean in 2004, Hurricane

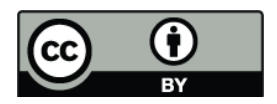

Correspondence to: $\mathrm{H}$. Taubenböck (hannes.taubenboeck@dlr.de)
Katrina in New Orleans, USA, in 2005, the cyclone Nargis in Myanmar in 2008 or the heavy monsoon floods in Pakistan in 2010. To give an example of the economic impact of the disastrous flood in the Elbe River basin in August 2002, rough cost estimates are $\sim 3$ billion $\$$ in the Czech Republic and more than 9 billion $\$$ in Germany - the worst flood ever in Europe (Becker and Grünewald, 2003). Worldwide flooding is probably the number one cause of losses from natural catastrophic events, and even though the spatial impact is mostly local, regional or sometimes national, the consequences are often global (cf. Fig. 1).

The UN/ISDR (2004) determined that the risk to a particular system has two factors. One factor is the "hazard" itself, which is a potentially damaging physical event, phenomenon, or human activity - in our case floods - that is characterized by its location, intensity, frequency, and probability. The second factor is the "vulnerability" of a system (e.g. an urban area), which denotes the relationship between the severity of the hazard and the degree of damage caused. Thus, risk results from the future interplay of a hazard and the various components defining vulnerability e.g. physical, demographic, social, economic, ecologic or political components (Taubenböck et al., 2008). As flood risk is a function of the flood hazard, the exposed values and their vulnerability, the increase in flood losses must be attributed to changes in each of these aspects (Kron, 2003). Climate change and urbanization are arguably the most dramatic driving forces of global change. The clash of a climatologically driven increase of natural hazards with explosive, uncontrolled urban sprawl and changing urban patterns contains an increasing risk. On the one hand, statistics show a continuous increase of hydrological disaster events since 1980 (Munich Re Group, 2009). In 2008, the NatCatService of the Munich Re's database documented 750 loss events, with 292 of them floods and landslides (Fig. 1).

Published by Copernicus Publications on behalf of the European Geosciences Union. 
Number of natural catastrophes 1980-2008

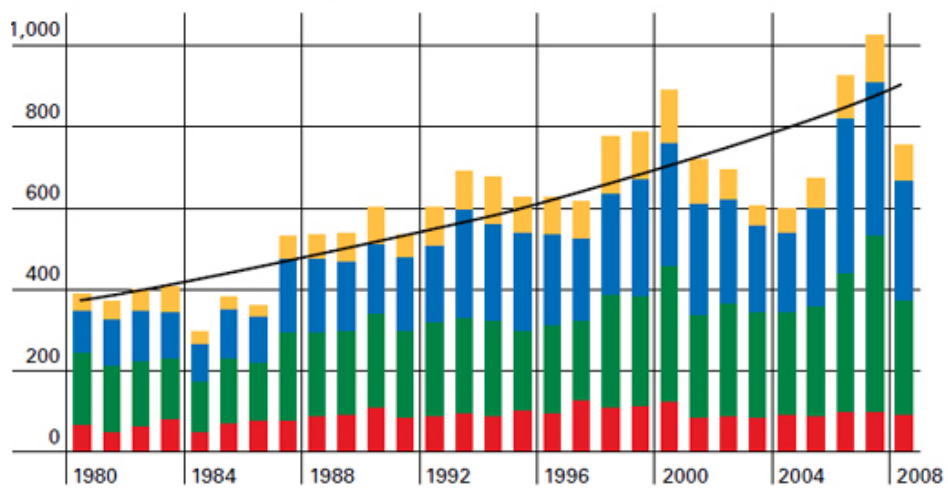

- Geophysical events

Earthquake, volcanic eruption

Meteorological events

Tropical storm, winter storm, severe weather, hail, tornado. local storm

- Hydrological events Storm surge, river flood, flash flood, mass movement (landslide)

Climatological events Freeze, wildland fire, drought

- Trend

Munioh Re Topics Geo 2008

Fig. 1. Number of natural catastrophes since 1980 (Source: Munich Re Group, 2009).

On the other hand, trends imply that almost all the expected world population growth until 2030 will be absorbed by urban areas (UN, 2007). Especially mega cities - cities with more than 10 million inhabitants (Mertins, 1992) - feature an enormous dimension of quantitative growth, a high concentration of people, infrastructure, and economic power. Furthermore, the synchronism, complexity, and interaction of diverse urban processes imply high vulnerability (Taubenböck et al., 2009a). This high pressure on urban space and hence, fast uncontrolled spatial growth and densification creates settlements in inappropriate areas most likely to be exposed to natural hazards.

During the past decades airborne and spaceborne remote sensing technology along with geographic information systems (GIS) have become the key tool for flood monitoring (Brivio et al., 2002; Horritt et al., 2003; Mason et al., 2007; Nirupama and Simonovic, 2007; Sanyal and Lu, 2004; Wang, 2004; Voigt et al., 2007; Zhang et al., 2008). Development in this field has evolved from optical to radar remote sensing, which has provided an all-weather capability compared to the optical sensors for the purpose of flood mapping. As different remote sensing sensors have a different ground resolution and varying flood/water detection potential, it is important to be aware of such limitations when processing the respective flood masks in GIS operations or when generating flood maps. Our study focuses on the capabilities of multi-source earth observation data, techniques and applications to support hazard analysis, vulnerability assessment, flood risk identification, and a more accurate flood risk modelling and the development of mitigation strategies as a basis to support substantial decision-making before, during and after a flooding event. We provide insight into multi-sensoral, multi-scale and multi-temporal products as well as continuative analysis using interdisciplinary approaches - highlighting both, the hazard and the vulnerability perspective.

\section{Data sets}

Remote sensing applications in the field of flood risk assessment and management can draw from a wide range of data sets with differing capabilities. We use active and passive as well as spaceborne and airborne sensors to provide a large database for specific flood-related problems. Depending on the particular spatial resolution and recurrent period, different flood-related parameters ranging from global to regional or even local scales can be derived (Schultz, 1994; Tholey et al., 1997).

We use spaceborne optical sensors like MODIS, Landsat or Ikonos, as well as active sensors like TerraSAR-X and the Shuttle Radar Topography Mission (SRTM). The MODIS sensors acquire surface data from the visible to the near-infrared through mid-infrared wavelengths (with 36 spectral bands) with a swath width of $2300 \mathrm{~km}$. Although the spatial resolution of MODIS data only ranges from $250 \mathrm{~m}$ ( 2 visible bands), to $500 \mathrm{~m}$ ( 5 visible to shortwave infrared bands), and to $1000 \mathrm{~m}$ (29 visible, near infrared, shortwave infrared, and mid-infrared bands) (Parkinson and Greenstone, 2000), the sensor allows monitoring the often large dimensions of flooding events. The capabilities of the Landsat systems have allowed monitoring urbanization on urban footprint level since 1972 and provide a swath width of $185 \mathrm{~km}$ a large overview on current flood situations. The high-end geometric capability of Ikonos enables the derivation of highly detailed urban structures or current flood masks. Apart from these data sets, many sensors with similar technical details allow comparable analysis, examples ranging from medium to very high resolution are SPOT, IRS, Rapid Eye, Cartosat, QuickBird, GeoEye-1 or WorldView-I and II. Satellites from EUMETSAT enable monitoring current weather situations to include predictions of heavy rainfall or cyclones, etc.; however, this field of application is not part of our study. The active sensor TerraSAR-X allows the continuation of monitoring urban 


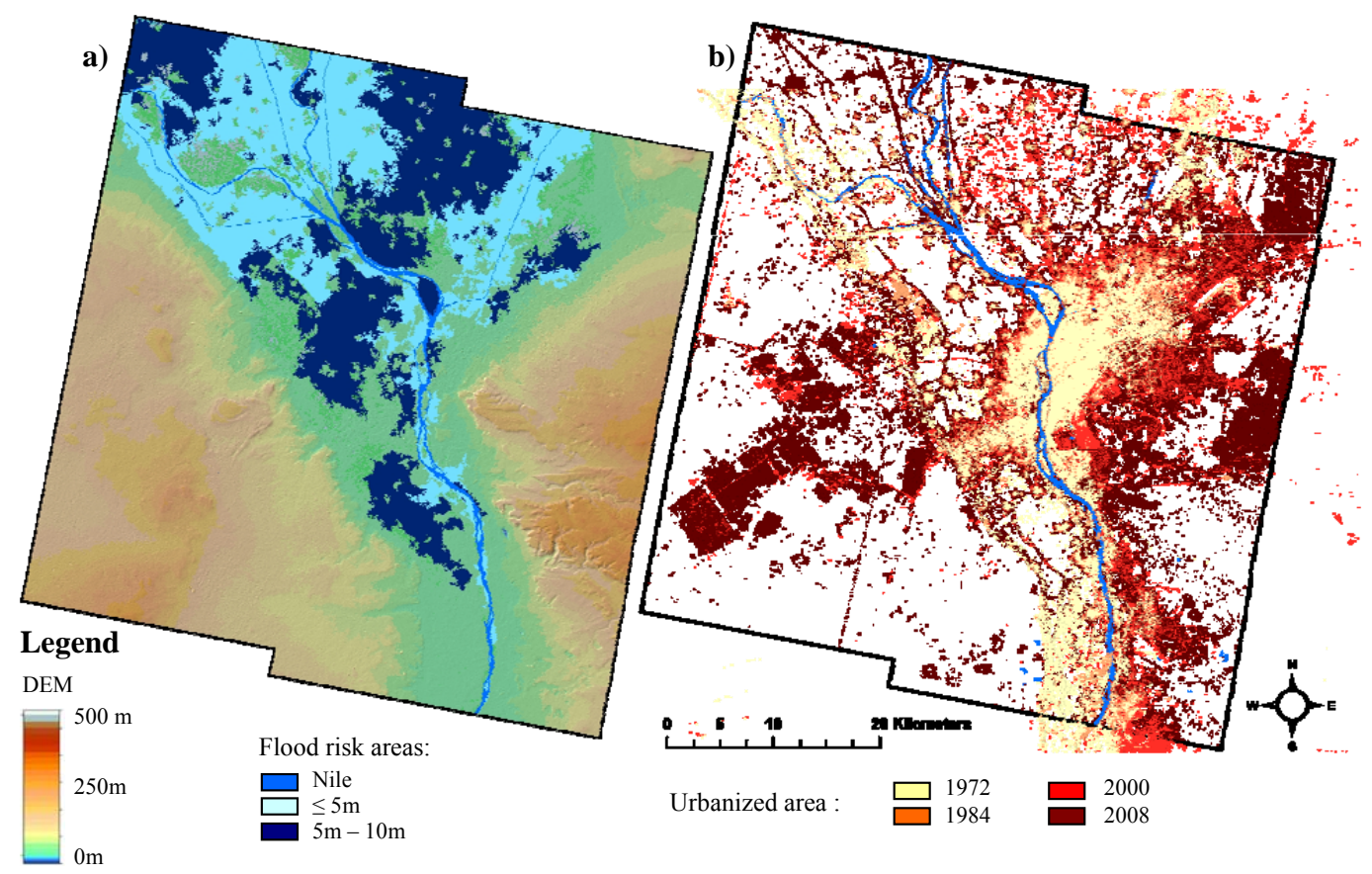

Fig. 2. (a) Scenario-based assessment of flood prone areas at the mega-city of Cairo (b) Urbanization on an urban footprint level from 1972 until 2008.

footprints as well as the derivation of flood masks. For up-to-date monitoring, radar sensors are preferred due to their cloud penetrating capability (Brakenridge et al., 2003). Examples for similar missions are CosmoSkymed, Radarsat or ALOS. In addition, an interferometric digital elevation model (DEM) based on X-and C-band data from the SRTM is used to analyze the terrain situation. It is a surface model with a pixel-spacing of $1 \times 1$ arc seconds to a maximum of $3 \times 3$ arc seconds, which are $\sim 25-90 \mathrm{~m}$ (Marschalk et al., 2004), and thus enables a rather coarse overview between the degree of latitude of 60 north and south. Future missions, like TanDEM-X will provide a global coverage with a higher geometric detail of about $12 \mathrm{~m}$ (Bartusch et al., 2010).

In addition to this, we use an active airborne laserscanning system (ALS) which provides LiDAR (Light Detection and Ranging) data. ALS is an active remote sensing system which measures the running time of a laser beam between the sensor and the reflecting surface on ground and back. By means of GPS (Global Positioning System) and INS (Inertial Navigation System), the absolute position of the reflecting object in $\mathrm{x}, \mathrm{y}$ and $\mathrm{z}$-direction can be detected (Hofmann, 2005). The surface model used in this study features a geometric resolution of $1 \mathrm{~m}$, enabling highly detailed extraction of urban objects or flood-prone areas.

\section{The capabilities of remote sensing to assess and manage risk and vulnerability}

Well-founded decisions are a prerequisite for the formulation of successful mitigation, response, preparedness, and recovery strategies (Plate, 2002). To a large extent, however, successful strategies depend on the availability of accurate information presented in an appropriate and timely manner. In the following we will formulate seven main questions for the decision-making process regarding assessment and management of flood risks in urbanized areas. These questions serve as a guideline to show the capabilities of remote sensing to contribute to this complex task:

- Where are exposed areas?

- What would be affected?

- How many people would be affected?

- Who will be affected?

- How great will the damage be?

- What is the current situation and which immediate reaction is necessary?

- Which damage grades can be classified?

\subsection{Where are exposed areas?}

Problems involved in hazard identification, risk assessment, and developing mitigation solutions are inherently spatial in nature. In our first example we use a DEM based on SRTM data to assess the spatial distribution of potentially endangered flood areas at the mega-city of Cairo, Egypt. The course of the river is derived from the Landsat ETM+ sensor using an object-oriented approach combining spectral 
information with shape and context information (Abelen, 2010). Subsequently, the surface height values relative to the river elevation are calculated. Using the relative height differences between the river and its surroundings in combination with neighbourhood information and a surface height dependent region growing algorithm starting at the river Nile, we identify endangered lowland areas. The limitations of the approach, however, lie in the constricted accuracy of the SRTM data set. Nonetheless, with a relative horizontal accuracy of $6 \mathrm{~m}$ and better (Rabus et al., 2003) the straight-forward approach lets us assess scenario-based flood prone areas to obtain a first basic and coarse overview on the hazard perspective (Fig. 2a).

From the vulnerability perspective, especially areas with progressive urbanization increase the risk of flooding considerably (Nirupama and Simonovic, 2007). Multi-temporal data sets enable monitoring urbanization over time to provide insight on the vulnerability perspective. We used Landsat data from the years 1972, 1984 and 2000 and TerraSAR-X stripmap data from the year 2008 to monitor urbanization over time. Our main goal was to identify the urban built-up areas in order to measure the changes in extent, direction, speed and pattern of the urban extensions over the time interval. For that purpose the classification methodology is based on an object-oriented hierarchical approach (Abelen, 2010; Thiel et al., 2008). The object-oriented, fuzzy-based methodology was implemented to combine spectral features with shape, neighbourhood, context and texture features. The capabilities of these data sets enable an area-wide, up-todate and continuous long-time monitoring of urbanization on an urban footprint level with accuracies of more than 90\% (Taubenböck et al., 2009a). Our example shows the highly dynamic process of spatial urbanization from 1972 until 2008 at the mega-city of Cairo, giving insight into spatial expansion of potentially vulnerable areas (Fig. 2b). Overlapping the scenario-based spatial hazard impact and the detection of vulnerable areas on urban footprint level enabled us to identify where potentially affected areas are located and to quantify their dimensions.

In our second example we present a spatial risk analysis using past sample flood events for the city of Gorakhpur in India. Gorakhpur lies in the Lower Rapti River Basin (LRRB) and is a highly flood-prone and vulnerable urbanized area with its dynamic urban growth and currently 3.8 million inhabitants. The inundation events for the years 1998 and 2007 were extracted using MODIS data to analyze the spatial extent of flood-affected areas. Furthermore, for the particular time-steps we used Landsat data to extract a thematically higher resolved land-cover map than in our first example (cf. Fig. 2). The National Remote Sensing Agency (NRSA) classification scheme of 1995 for urban areas (level 1) was adopted to prepare the land use/land cover maps for the years 1998 and 2007 using a maximum likelihood algorithm with an overall accuracy of $81 \%$ for 1998 and $83 \%$ for 2007 (Shukla, 2009) (cf. Fig. 2).
Table 1. Flood risk in and around the Gorakhpur urban center.

\begin{tabular}{|c|c|c|}
\hline \multirow[t]{3}{*}{ Land use class } & \multicolumn{2}{|c|}{ Lower Rapti River Basin (LRRB) } \\
\hline & (1998) & (2007) \\
\hline & \multicolumn{2}{|c|}{ Area $\left(\mathrm{km}^{2}\right)$} \\
\hline Rapti River & 266.30 & 266.30 \\
\hline Flood-affected areas & 1394.58 & 1115.96 \\
\hline Urban settlement & 46.68 & 40.68 \\
\hline Agricultural land & 2383.25 & 2667.87 \\
\hline Total area LRRB & 4090.81 & 4090.81 \\
\hline
\end{tabular}

The map of flood-affected areas has been superimposed on the land use map of LRRB derived from remotely sensed images to visually show and quantify the past spatial impact on different land use classes of floods in 1998 and 2007 (Fig. 3). The results in Table 1 show that more than $40 \%$ of the urban settlements were submerged and about $2500 \mathrm{~km}^{2}$ of agricultural land was destroyed in the floods of 1998 and 2007. The main railway lines connecting Gorakhpur to Lucknow and Varanasi City were flooded and the area was cut off from other parts of India. The National Highways (NH) Nos. 28 and 29 were washed away in many places and road traffic stands halted for many days. The 2007 flood in LRRB was a record-breaking flood which affected about every part of the basin and major parts of Gorakhpur city. $40.68 \mathrm{~km}^{2}$ out of $67.75 \mathrm{~km}^{2}$ of total urban area was under the flood water for a few days. This urban center is one of the largest in the Eastern Uttar Pradesh, India, which has a very high density of population in the basin as a whole: thus, the physical and economic losses due to flooding were very high. An additional survey during 2007 and 2009 resulted in 250 out of total 777 households with reported loss of food crops at the LRRB due to flood. In monetary terms, the loss was more than 220 US-Dollars per household and few times even more than 1.100 US-Dollars. In a country in which the average income per person and year was 800 US-Dollars in 2006, this impact is of high significant. Overall, this clearly shows the immense local, regional and even national impact of the past flooding events around the Gorakhpur urban center.

\subsection{What would be affected?}

With a higher geometrical resolution of remotely sensed imagery, a higher level of detail for vulnerability analysis - especially within urban areas - can be achieved. Very high resolution optical satellites - such as Ikonos, Quickbird, WorldView I and II or GeoEye - provide a geometric detail of up to $41 \mathrm{~cm}$ which makes it possible to identify even small urban structures - such as single buildings or streets. Nonetheless, monoscopic spaceborne satellite imagery is mostly limited to two-dimensional analysis of its content. In combination with DSMs (Digital surface models) obtained by airborne laserscanning or stereoscopic 

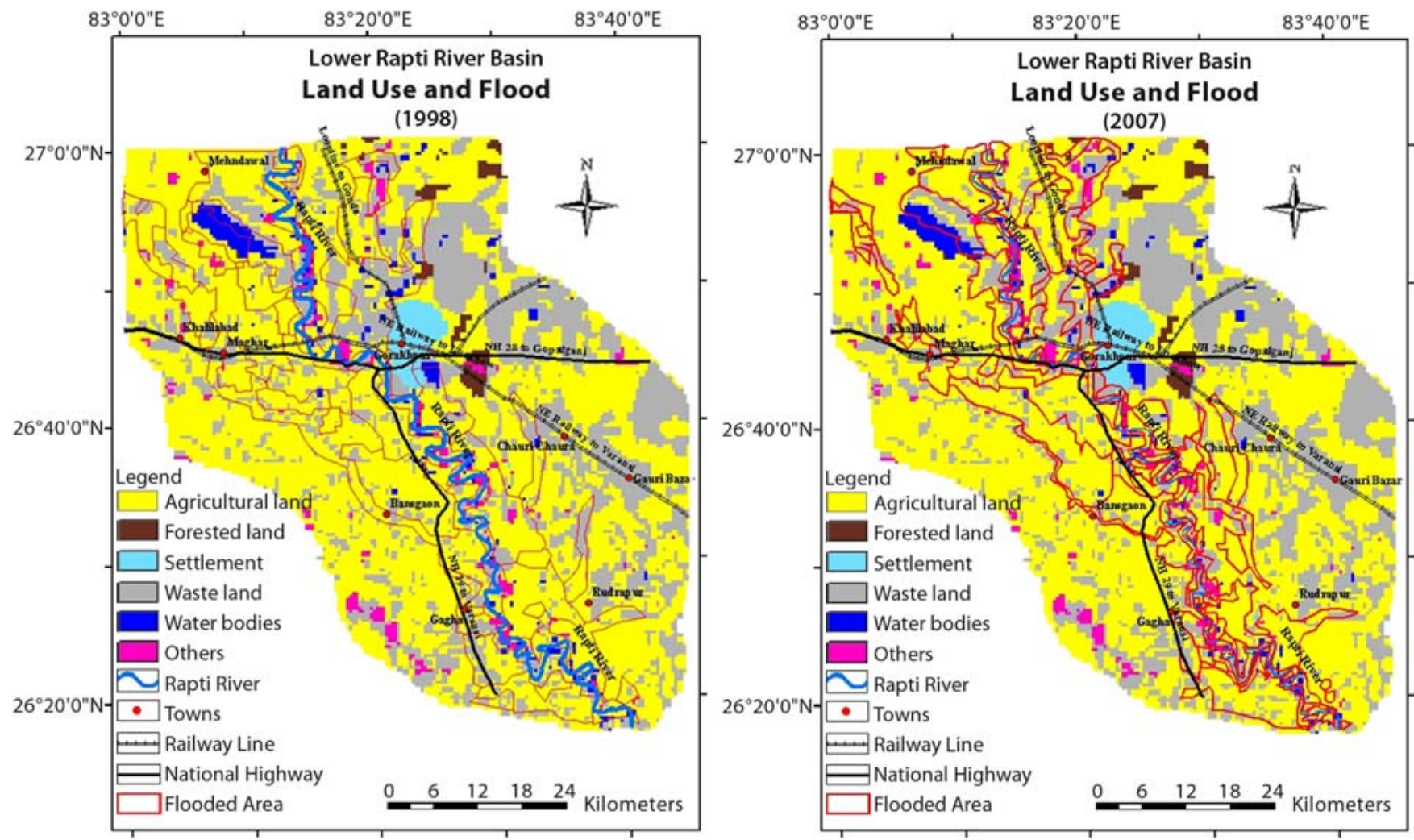

Fig. 3. Spatial impact of flood events at Gorakhpur, India.

techniques, detailed information about the third dimension can be integrated.

An object-oriented image segmentation and classification approach was developed to retrieve such information on a very high level of detail based on VHR optical satellite imagery and ALS data (Esch, 2006; Taubenböck et al., 2010; Wurm et al., 2011). The methodology was implemented as a modular-based solution, which allows the user to analyze either single or combined data sets. With subsequent processes of segmentation optimization, multilevel classification, region-growing and fuzzy-based decision fusion based on shape, hierarchical, contextual and spectral information of the image data, highly detailed land-cover information can be extracted. Further differentiation of the urban morphology is achieved by utilization of 3-D data.

The height information in the ALS data, with a geometric resolution of $1 \mathrm{~m}$, makes it possible to delineate clear building boundaries in the first place and to enhance them with three-dimensional information in the second place. This leads to a proper representation of the urban fabric in terms of a 3-D city model (Fig. 4). Together with the size (area, elevation) and the shape of a building, it is possible to classify it as one of the various building types, such as "semi-/detached", "building blocks","row houses" or "high-rise buildings" just to name a few. A spatial intersection of physical building structures with possibly flooded areas leads to a quantification and localization of possibly affected structures. Additional knowledge of flood depths (cf. 3.7), together with building height makes it possible to assess possible damage to the individual building or to assess possibilities for vertical evacuation of its dwellers (cf. Sect. 3.5). Furthermore, land-cover classes ("buildings", "streets', "water", "trees/woods", "grassland") give a detailed impression of the physical furnishing of the area.

A combined analysis of the 3-D city model and the landcover classification may lead to a sophisticated assessment of impervious surfaces within the city (Esch et al., 2009). This parameter can be of high importance to model the run-off during a possible flood-event. Figure 4 shows a threedimensional view of the digital elevation model, the riverbed and the building structures overlaid with a predicted flood scenario $(\mathrm{EHQ}=$ Extreme run-off scenario) for a quarter of the city of Dresden, Germany.

Accuracy assessment has been performed on the land cover classification, revealing $81.2 \%$ correctly detected buildings and an overall accuracy of the land cover classification of $88.93 \%$. Building floors are derived by the mean elevation of each building divided by a mean floorheight, which was estimated as $3.35 \mathrm{~m}$. The overall accuracy 


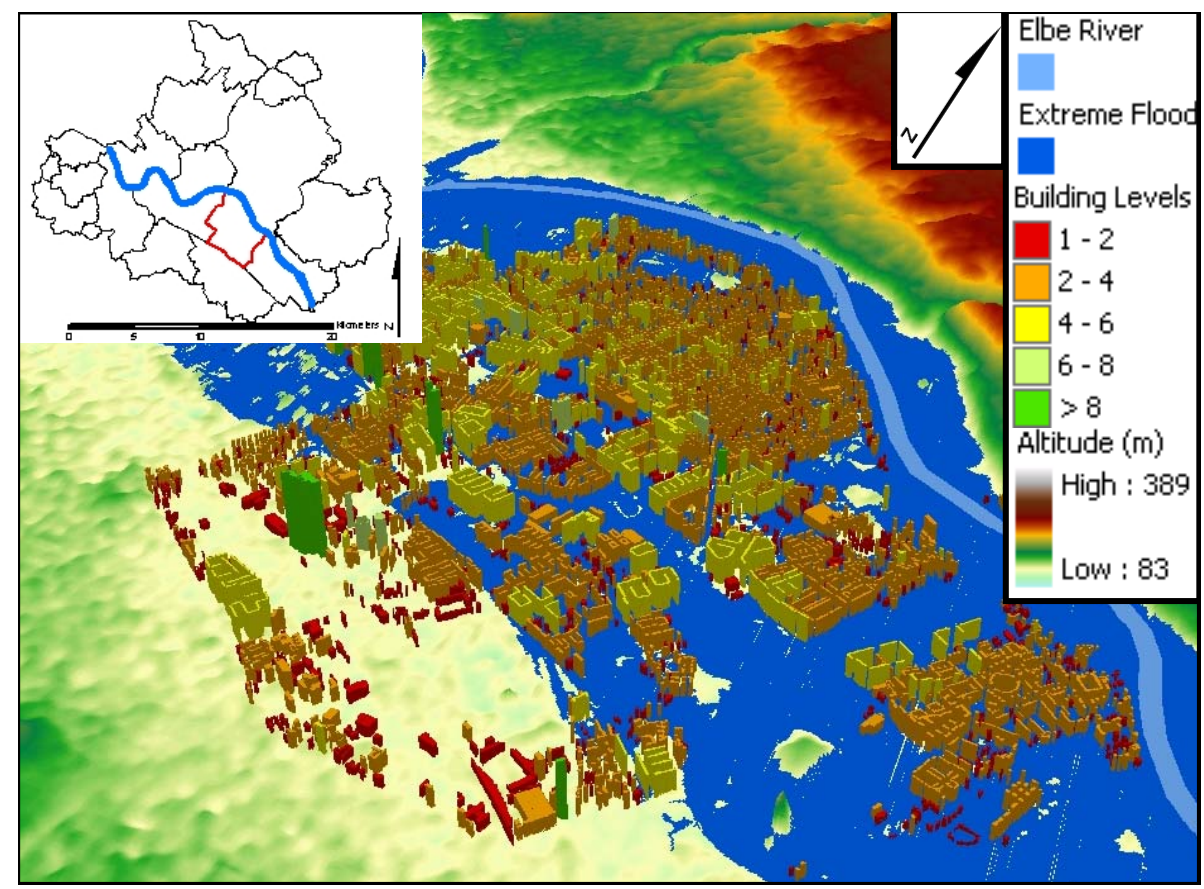

Fig. 4. Overlapping of flood scenario (EHQ) with structures of the city of Dresden.

of floor estimation shows that $91.40 \%$ of Dresden's buildings have been estimated with a maximum deviation of one floor (Wurm et al., 2009).

\subsection{How many people would be affected?}

Static urban morphology gives insight into the physical perspective of vulnerability. Correlating the static element of physical urban structures with the dynamic element of spatial and temporal behaviour of the population data distinguishes a demographic perspective on vulnerability (Taubenböck et al., 2007). The highly detailed 3-D city model derived by means of multi-source high resolution remote sensing data (cf. Fig. 4) is used as basis for inferring time-dependent population distribution on individual building level. Besides the physical characteristics of urban morphology - size and height of the buildings - three different land use classes, "commercial", "residential" and "mixed use", were assessed. Structural characteristics, in particular roof type, building size and alignment, percentage of sealed areas and location, were used for this purpose. Thus, land use can be integrated to consider the dynamic spatial shift of population between daytime and nighttime.

Different external input data determine the two different methodologies for calculating population distribution. On the one hand, statistical population data are based on the coarse spatial unit of administrative districts. A topdown approach distributes the total population according to urban structural characteristics derived from remote sensing data. Therefore, the ratios of the areas of corresponding homogeneous zones are calculated to relate living space to the total population. This enables a proportional spatial interpolation of the total population. In the other case, punctual population information derived from fieldwork is the starting point. A bottom-up approach uses a chronologically permuted methodology using the same structural characteristics of the urban environment. The result is a local distribution of the generalized total population information based on the spatial unit of a whole district. The benefit appears in the significant time-dependent spatial differences of population densities on an individual building level within the district. In our example of the mega-city of Istanbul, Turkey, the total population of the district Zeytinburnu is resolved into smaller units, resulting in a spatial coexistence of maximum extremes from open spaces with no inhabitants to more than 60000 inhabitants per $\mathrm{km}^{2}$ in high density residential built-up areas with buildings containing more than 7 floors. This provides more specific and systematic knowledge for time-dependent risk management (Fig. 5).

An accuracy assessment has been carried out based on population data within a $500 \times 500 \mathrm{~m}$ raster in Zeytinburnu (Erdik, 2002). For residential areas the accuracy assessment shows a consistent underestimation of $3.8 \%$ to $9.3 \%$, while for mixed and commercial areas a consistent overestimation of $20 \%$ and more has been identified. The absolute values in the corresponding test raster are consistently of the same dimension. Hence, the results of the accuracy assessment 


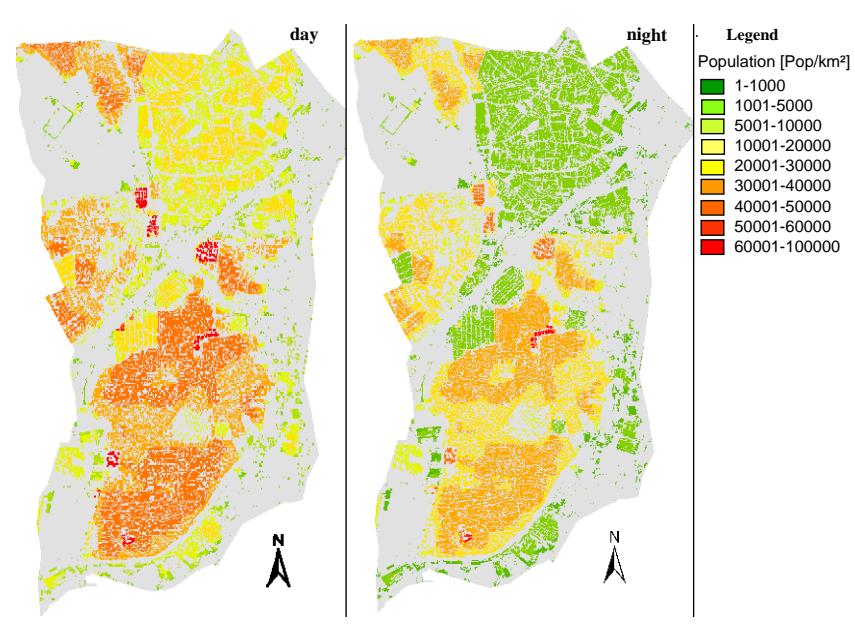

Fig. 5. Dynamic population distribution on an individual building level, mega- city of Istanbul, Turkey.

support the hypothesis that population distribution correlates directly with the structural characteristics of the urban environment.

This demonstrates the capabilities of remote sensing to spatially distribute demographic input parameters based on an analysis of urban structural characteristics. Of course, remote sensing cannot accurately map cadastral data, but it can provide a fast assessment of the correct dimension of a population based on a correspondence to the dynamic development in an urban area.

\subsection{Who would be affected?}

A city is the physical and architectonic reflection of the society that created it. Thus, the detailed knowledge on urban morphology implies not only information on how many people are living there, but also on who is living there (Taubenböck et al., 2009c). In the context of vulnerability, spatial information on social or economic questions is of crucial importance.

We use the hypothesis that populations living in urban areas showing almost similar physical housing conditions will have homogeneous socioeconomic and demographic characteristics (Anas et al., 1998; Hoffmeyer-Zlotnik, 2000). For our example - the tsunami-prone city of Padang, Indonesia - we combine the area-wide available statistical physical parameters describing the building stock of Padang per sector. These parameters - built-up density, average house size, average building height, location (cf. 3-D city model Fig. 4) derived from multisensoral remotely sensed data, enable us to identify physically homogeneous areas. Using these physical parameters, we then perform a semantic classification for the urban environment. The idea of semantic classification aims at a first assumed interrelation between physically homogeneous sectors within the complex urban morphology and the socioeconomic characteristics of people residing there. The terminology of the semantic classes is based on housing quality and location. The housing quality is assumed to be higher with rising building size or height and lower built-up density. We classify five different semantic classes - "slums (or informal settlements"), "suburbs", "low class areas" (LC), "middle class areas" (MC) and "high class areas" (HC). For every semantic class we assume typical physical conditions. UNHabitat (2007) defines e.g. slums as a household lacking at least one of the following: durable housing protecting against extreme climate change, sufficient living space, easy access to safe water and sanitation or security. As these parameters can not be integrated using earth observation data and methods, we use a definition based solely on physical parameters: highest built-up density measured within the urban environment with mostly one storey buildings, with the smallest buildings sizes. With the nomenclature "slum" the classification by solely physical parameters sets a first hint in the direction of assumed socioeconomic relevance.

To verify the hypothesis stated above, a field survey was conducted in the city of Padang (1000 buildings were sampled) to obtain information on the socioeconomic parameters of the population. In our example we tested whether a basic correlation with the classification based on the physical parameters and its subsequent semantic assumptions exists or not for the indicator "income". For this, we used the average values for socioeconomic parameters for every semantic class as well as the standard deviation as a measure of homogeneity within one semantic class. In a second step we analyzed whether certain semantic classes, like slums or low class areas, although located at different areas of the urban environment (e.g. at the coast close to the city centre or at a suburban area), show homogeneous socioeconomic parameters. For this we used location-based analysis of the same semantic classes for testing homogeneity. The results reveal a trend that basically confirms the hypothesis stated above for the sample parameter "income". In detail, the analysis shows that the classified slum areas as well as the classified suburb areas reveal lowest income values independent of their location within the urban landscape. We also find consistent rising income levels to the semantic classes "low class", subsequently to "middle class" areas, and for the "high class" in the southern area of Padang (Fig. 6) - thus confirming the initial hypothesis. In the central area we have no high class buildings, but in the northern area we observed unexpected variances - lower income of 'high class' areas compared to the "middle class" area.

Thus, remote sensing enables us to add the spatial component of socioeconomic vulnerability area-wide in an urban environment - answering the question 'who' would be "where" potentially affected by a flood event. In detail, the results allow information on whether affected areas are among the poor or not in its correct dimension. This indicator 


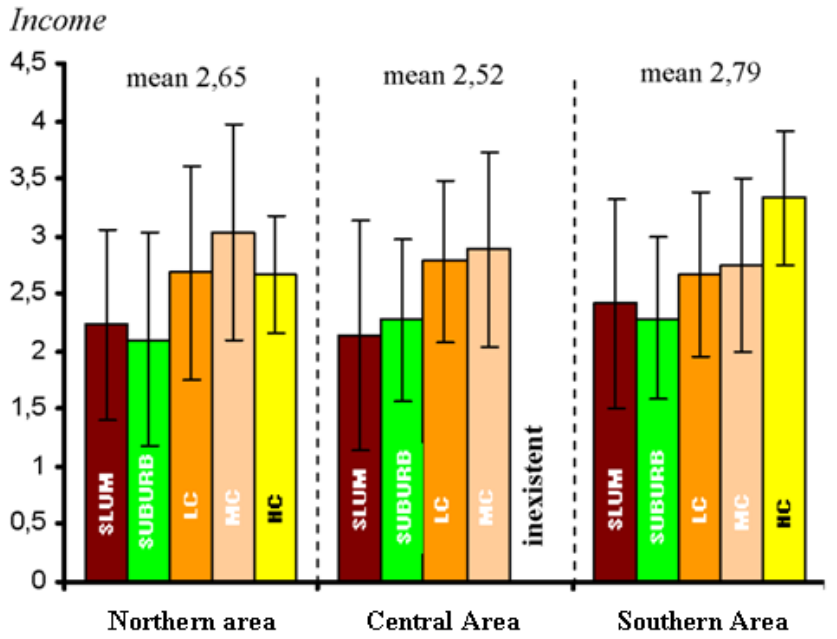

Fig. 6. Location-based mean value correlation of semantic classes and the socioeconomic parameter income and their standard deviations.

- as one of many - defining socioeconomic vulnerability e.g. reveals insight into the coping capacity of the people living there.

\subsection{How large will the damage be?}

In more dynamic flooding events like tsunamis or storm surges, the physical stability of the structures most likely hit are of critical importance. The highly dynamic urban systems, their large extensions as well as their unmanageable amount of structures make surveying the complete building stock for civil engineering out of reach for time- and cost reasons (Münich et al., 2006; Taubenböck, et al., 2009b). Interdisciplinary approaches show value-adding, providing correlations between punctual field surveys to assess building vulnerability with civil engineering methods and area-wide and up-to-date extrapolation on homogeneous building types by remote sensing techniques.

Taubenböck et al. (2009b) used the capacity spectrum method to correlate building types derived by remote sensing with building stability for an earthquake impact. The capacity-spectrum method was developed in the 70s rooted in John A. Blume's "Reserve Energy Technique" (RET) (Freemann, 2004). The capacity-spectrum method is a simplified, nonlinear, static methodology. The capacityspectrum method was enhanced for example in the HAZUS program (Fema, 2007) and standardized for California in the ATC 40 report. The capacity spectrum method is divided in three main steps: in the first step the seismological impact is calculated using a response-spectrum. Secondly, the physical characteristics of various building types, in our case derived from remote sensing data, show their global load capacity resulting from the specific strength and deformation characteristics of the different components of

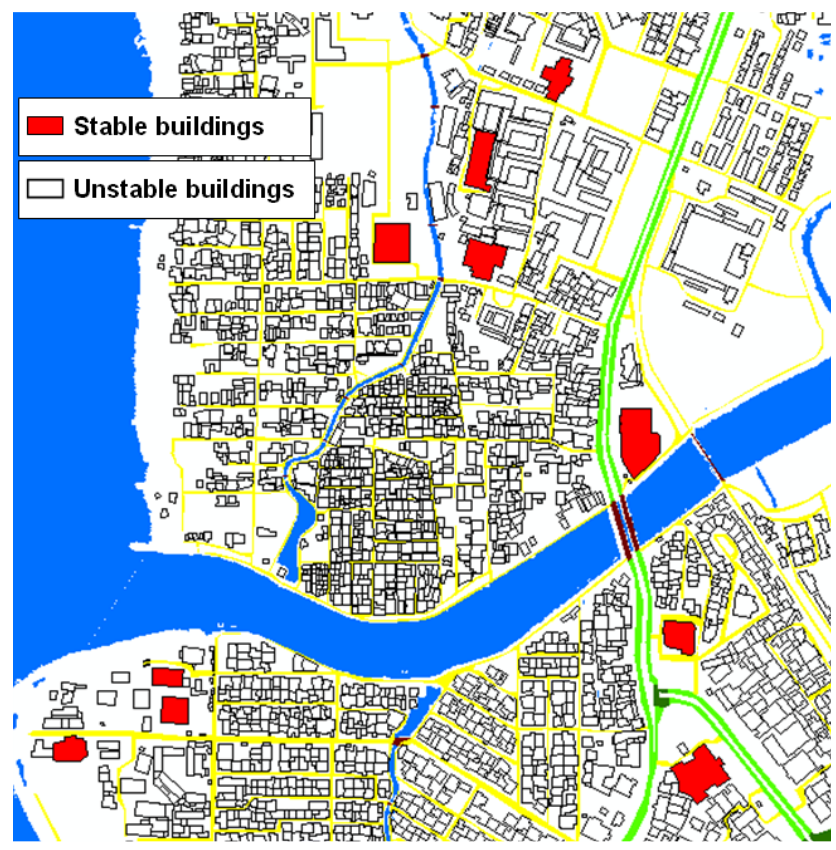

Fig. 7. Identification of scenario-dependent stable structures combining the capabilities of civil engineering and remote sensing.

the structure. In the third step the correlation between the expected deformation and the probability of an expected damage grade is derived.

Leone et al. (2007) correlated physical parameters of buildings visible from space with damage grades surveyed after the 2004 tsunami in Banda Aceh, Indonesia. In our example, a field survey based on 500 sample houses was conducted from civil engineers to analyze building stability. Physical tests like the hammer test as well as surveying physical parameters such as building material, height, etc. has enabled a detailed assessment of building stabilities with respect to different wave impact intensities. The 3-D city model derived from multi-source remote sensing data (similar to Fig. 4) enabled correlation of punctual knowledge on building stability to area-wide existent physical parameters of the building stock like height, size, floor plan or roof type. Thus, extrapolation enabled us to identify safe structures and highly vulnerable structures as well with a probability of $86 \%$. Figure 7 shows highly vulnerable as well as stable buildings at the coast-line of the tsunami-prone city of Padang, Indonesia (Taubenböck et al., 2009b; Kass et al., 2007). These data sets enable the assessment and quantification of probable damage depending on the particular tsunami-scenario. They are the basis for developing mitigation strategies like evacuation planning. 


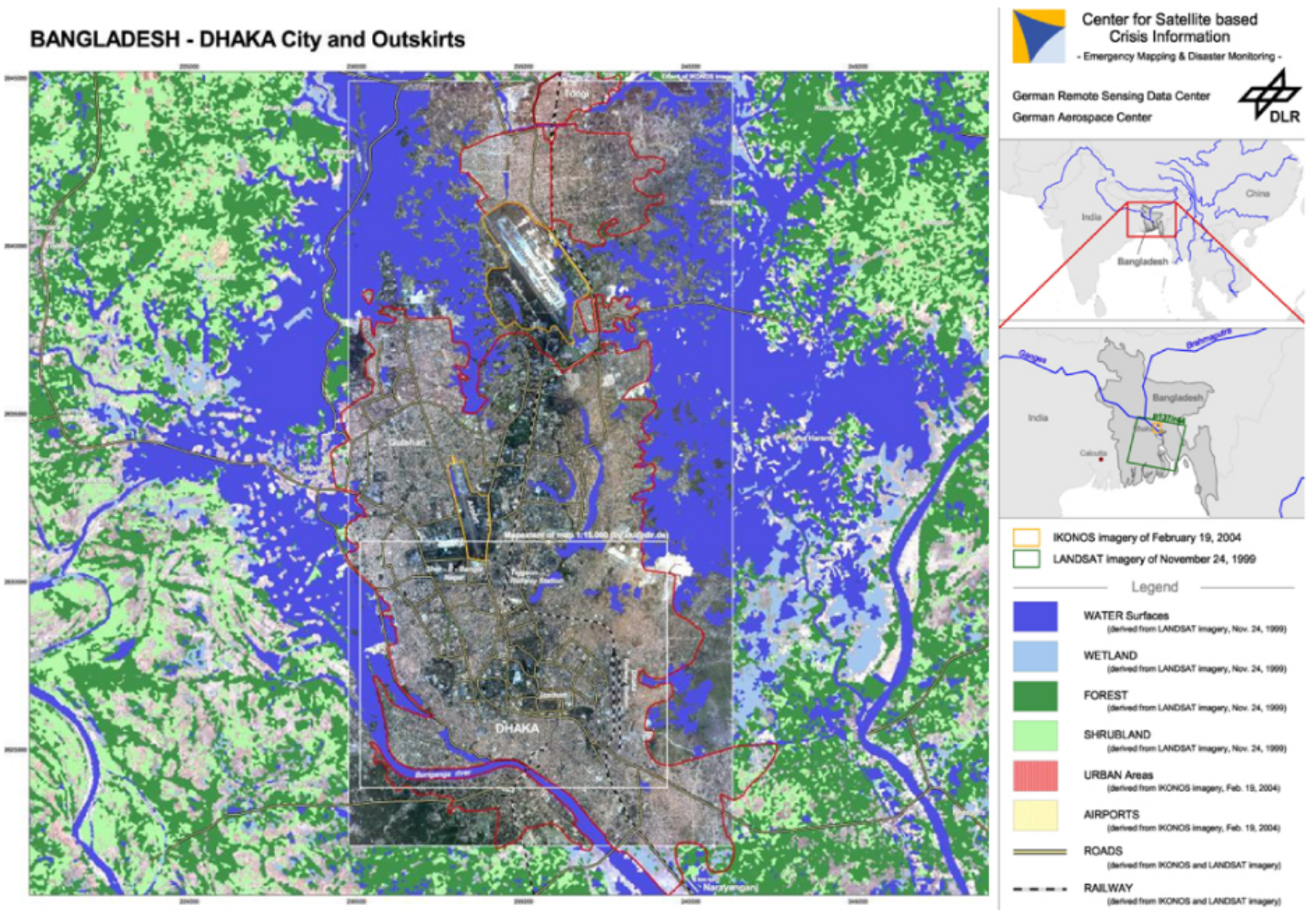

Fig. 8. Flooding of the megacity of Dhaka: rapid mapping result produced at DLR-ZKI to derive up-to-date spatial information for relief operations www.zki.dlr.de.

\subsection{What is the current situation and which immediate reaction is necessary?}

With an increasing availability of manifold space- and airborne sensors sets (cf. Sect. 2) and the improvement of image analysis techniques, remote sensing enables accurate and timely analysis of satellite data recorded during or shortly after a flooding event to obtain current information on de facto impacts (Domenikiotis et al., 2003; Voigt et al., 2007).

Delineation of flooded areas in various optical data sets is commonly based on the assumption that water has very low reflectance in the near-infrared portion of the spectra. Classification algorithms for water areas in radar data sets commonly use the low backscatter signal. In any case, flood is a wave phenomenon, where different inundated areas are presented on the satellite images taken at different times during the flood. The time of acquisition of satellite data does not generally coincide with the time of flood peak or maximum inundated area (Islam and Sado, 2000). Thus, the example in Fig. 8 shows an up-to-date multi-source product produced by the DLR-ZKI (Center for Satellite Based Crisis Information), mapping only the maximum spatial extension of flooding by a combination of Landsat and Ikonos data acquired at the available different times.

The automatic algorithms for mapping water bodies or floods (Martinis et al., 2009) from earth observation data show limitations e.g. in areas of shallow water bodies, of vegetation masking the water or in urban areas with occlusion effects (Hahmann et al., 2008). Figure 8 shows the dimensions and locations of flooded areas of the megacity of Dhaka, Bangladesh during the heavy monsoon floods in 1999 and provides the capability to assess and quantify affected buildings, infrastructure and people.

Accurate and spatially precise information on the damage caused is of vital importance for rescue and relief operations and for mobilizing resources for repair and recovery (Pesaresi et al., 2007; Saito et al., 2004). Thus, critical information for coordinating and directing rescue and recovery operations as a basis for supporting, managing and coordinating relief activities is promptly available. 


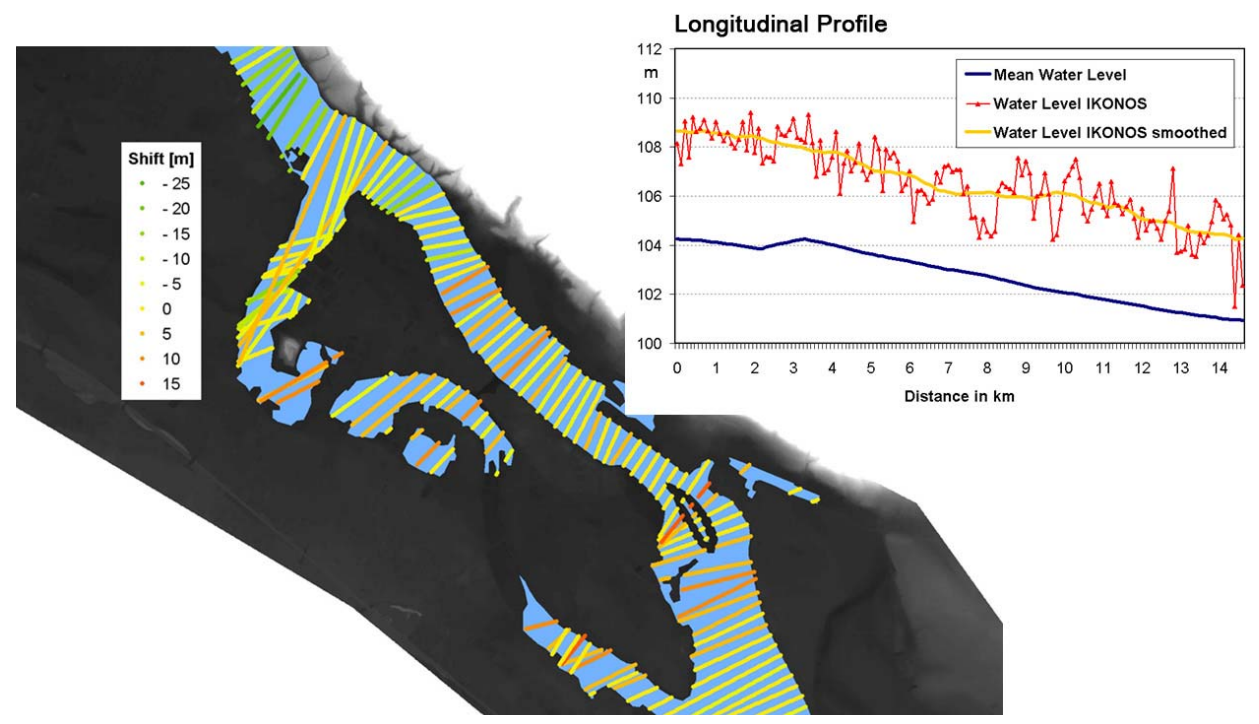

Fig. 9. Illustration of the IKONOS flood mask overlaid on the LiDAR DEM for a section of the Elbe River southeast of Dresden. The cross-section profiles are arranged perpendicular to the centerline of the river. The color represents the lateral shift of the cross-section flood profiles in relation to the underlying terrain (green $=$ shift to the left, red $=$ shift to the right). Additionally, the longitudinal profile of the river reach is depicted showing the mean elevation of the individual cross-sections in red. The smoothed yellow line serves as reference water level for the flood depth delineation.

\subsection{Which damage grades can be identified?}

Flood depth is considered as the most important indicator of the intensity of the hazard (Islam and Sado, 2000; Islam et al., 2001; Townsend and Walsh, 1998; Wadge et al., 1993) and is often used as the main input parameter for damage models (Thieken et al., 2005). Based on a flood mask derived from earth observation data or hydraulic modelling, flood depths can be theoretically derived and categorized when the flood extent is combined with elevation data. However, the mapping of flood depth is much more realistic when data from a real flood event is used instead of a statistically derived HQ100. To demonstrate the flood depth delineation, we used a high resolution Ikonos image taken one day after the peak of the Elbe flood 2002 together with a high resolution DEM derived from LiDAR.

Earth observation satellites are an important instrument for flood mapping and monitoring. However, the temporal and spatial constraints of the satellite sensor must be taken into account with respect to the dynamic characteristics of a flood. A satellite image of a sun-synchronous polarorbiting satellite (such as TerraSAR-X, Radarsat or Ikonos) is only a snapshot of the time of satellite overpass. The ground resolution and the water detection capacity are highly influenced by the spatial and spectral characteristics of the sensor. Due to the complex interaction of the active (from SAR) or passive (optical) radiation and the earth's surface which is recorded by the satellite sensor, a number of uncertainties may be inherent in the data. For the adequate estimation of the water level, it is necessary to determine the accurate position of the flood water boundary. In order to achieve this task, a high resolution DEM (e.g. from LiDAR) and accordingly high resolution satellite data such as from TerraSAR-X, COSMO-SkyMed or the optical sensors (cf. Sect. 2) are required. However, it must be considered that each flood mask carefully derived even from high resolution satellite data still includes some residual geometric and/or thematic classification errors. Such errors have to be minimized when the flood masks are intersected with high resolution DEM (Zwenzner and Voigt, 2009).

The technique presented here is based on the concept of locally fitting a carefully processed flood mask into high resolution digital elevation data sets (Meinel et al., 2003; Zwenzner and Voigt, 2009). For the initial parameterization of the flood plain, cross sections were established perpendicularly to the river centerline. Each cross section was then intersected with the flood mask and the flood profiles were derived as shown in Fig. 9. These flood profiles display a simplified representation of the flood mask and allow the incorporation of the vertical component which is added from the DEM. On the basis of the 3-D representation of the flood mask, it can be checked and adjusted in reference to the underlying terrain. Displayed in Fig. 9 is the lateral shift of each individual flood profile. This is based on the assumption that the water level on the left and the right river bank is equal. A systematic shift for all profiles would be an indicator for a geometric displacement of the entire water mask. In this case the geo-referencing of the satellite image would have to be improved or methods applied that improve the positional accuracy of the satellite derived flood mask (Schumann et al., 2006). 


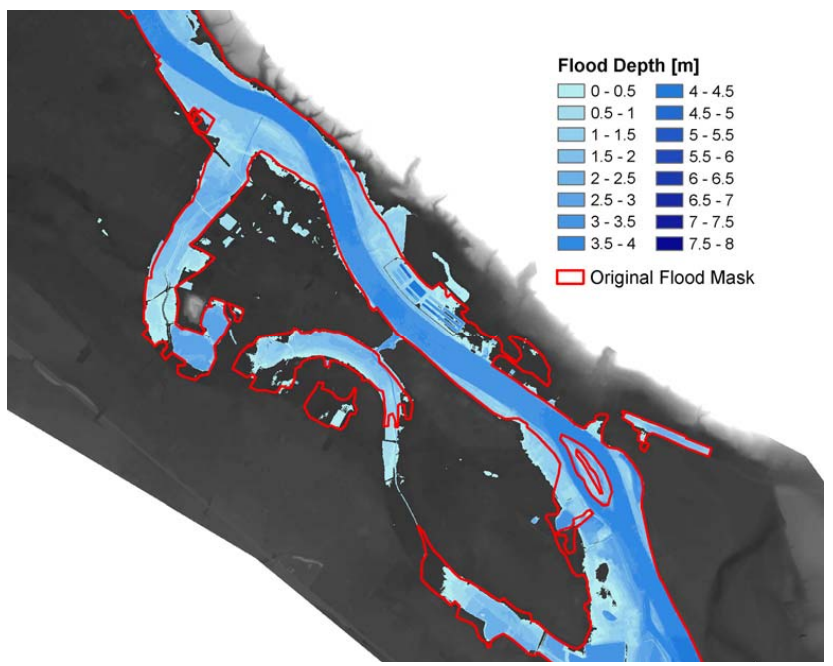

Fig. 10. Flood depth map of the Elbe River region southeast of Dresden showing the result of the computed flood depth and the resulting flood extent at the time of the Ikonos satellite overpass compared to the original flood mask.

The variability in the lateral shift of the flood profiles shown in Fig. 9 is mainly caused by minor classification errors due to vegetation or urban structures on either the left or right river bank (Horrit et al., 2003). Small residual geometric displacements or residual errors in the DEM may also be the cause for the lateral offset of some flood profiles. For each of the cross-section profiles, the elevation of the water level can then be extracted from the DEM at the position of the left and the right border of the flood (Matgen et al., 2007). The mean water level for each individual flood profile is then plotted versus the longitudinal profile of the river reach as it is illustrated in Fig. 9.

The significant variation of the flood levels (shown in red) can be attributed to the above-mentioned minor geometric and classification errors within the flood mask. Depending on the slope of the terrain, a slight horizontal error can cause a significant variation in vertical direction. In order to reduce the variation of the water levels and to eliminate outliers, a moving average was applied on the sequence of all cross sections over the longitudinal profile. The resulting smooth water surface, depicted by the yellow line in Fig. 9 (longitudinal profile) looks much more realistic and is used as the reference water level. If available, water gauge or ground truth data should be used for the validation of the reference water level. In the next processing step, each of the individual flood profiles were adjusted according to the modified reference water level from the longitudinal profile. This means that the flood profiles were trimmed or extended to achieve coherence with the underlying topography. The resulting flood profiles were then transformed into a Triangular Irregular Network (TIN) and a 3-D water surface could be derived. By subtracting the elevation of the terrain from the elevation of the water surface, the flood depth could be calculated as shown in Fig. 10. In comparison to the derived flood depth, the original flood mask is drawn in red.

The proposed semi-automatic method has been developed within the context of the rapid mapping of flood parameters, such as flood extent and flood depth, as a contribution to disaster management operations or to the rapid estimation of flood damage. The requirements of such applications are fulfilled by the fact that computation time is negligible. However, the limitations in a rapid mapping case are data requirements on remote sensing data and high resolution topographic data. The proposed method stands in contrast to hydrological modeling approaches which are more complex with respect to data requirements, parameterization and computation time.

\section{Conclusion and stakeholder outreach}

Conventionally, flood emergency management, both public and private, usually responds to crises rather than being concerned with the broader issues of vulnerability and its management (Shrubsole, 2001). One reason for this is the lack of information available to assess future flood events. The outline of this study showed the manifold capabilities of multi-source remote sensing to support decision making in the fields of risk and vulnerability assessment, sustainable development, ad-hoc coordination and management of rehabilitation before, during and after flood events.

The results show the capability of remote sensing to provide multi-scale and multi-temporal products for specific questions. A synoptic area-wide overview shows the assessment of potentially flood-prone urban areas, based on a DEM and spatial urbanization over time increasing vulnerability for the mega-city of Cairo. Furthermore, past inundation events are mapped and overlapped with a higher thematic detail of urban land cover resulting in a quantification of land-cover specific flooding impact for the dynamic Indian city of Gorakhpur. Another example presents the current mapping of flooded areas at monsoon time for the mega-city of Dhaka. Future impact of potential tsunami waves is presented using an interdisciplinary approach combining methods from civil engineering and remote sensing. The assessment of damage grades is modelled by flood depth analysis in a post-disaster case. And in highest thematic and geometric detail, we have provided a vulnerability analysis overlaying a 3-D city model with river flood scenarios as well as a quantification of probably-affected people on an individual building level.

Remote sensing is often the only independent, areawide and up-to-date data source due to dynamic changes or inaccessibility of areas in today's mega cities, and thus indispensable. However, a knowledge gap between the stakeholder's data requirements or operational procedures and 
the progress applying remote sensing to flood management has been experienced. Thus, in the future, the focus on the science-user-policy interface needs to be strengthened. Furthermore, due to technical, and/or cost reasons, the full range of presented remotely sensed data is often not available unlimitedly for such large and dynamic mega cities. Another constraint is the difference between requirements and capabilities regarding accuracy of the products: the synoptic overview of remote sensing in the previous chapters shows area-wide and spatially highly-detailed information extraction, but the accuracy of cadastral data sets has not been achieved. On the one hand, accuracies of $80-90 \%$ and sometimes even higher provide an objective basis for decisions. On the other hand, these earth observation products are not established at the current legal foundation and now need to find juristic acceptance. With reservations to this limitation the presented methods and applications are transferable, and thus independently applicable up-todate. Even if all data sets are available, remote sensing can not provide the highest accuracies cadastral data sets provide. In any case, the practitioners view uncertainty as an unavoidable factor (Morss et al., 2005), and for substantial decision-making it is rather important to know the correct dimension or trend than the exact number.

The results of this overview have a direct application in the formulation of policies on land use planning and future balancing of urbanization through conservation means, as well as for ad-hoc coordination of rescue measures. Integrative workshops with stakeholders from the addressed cities in our study supported application-oriented development of products needed for governance. Some examples of these are transdisciplinary collaborations between scientists and decision-makers from the Disaster Management Centre (AKOM) at the mega-city of Istanbul or from the German Federal Office of Civil Protection and Disaster Management (BBK), or from the spatial planning institute in Padang. In the latter example, results from science are the basis for the development of an official tsunami risk mitigation plan. Furthermore, the rapid mapping products are permanently provided to German relief organisations, like e.g. the German Federal Agency for Technical Relief (THW), to coordinate and plan rescue measures. In conclusion, remote sensing provides a large spectrum of capabilities in the field of flood risk assessment and management and must become an essential tool for decision making.

Acknowledgements. The authors would like to thank the DFG/BMBF special Programme "Geotechnologies" - Early Warning Systems in Earth Management. Sponsorship Code: 03G0666A-E. We would also like to thank the city of Dresden for the provided digital surface model. Finally we would like to thank the Federal Office of Civil Protection and Disaster Assistance (BBK).

Edited by: L. Ferraris

Reviewed by: T. Kemper and another anonymous referee

\section{References}

Abelen, S.: Development of a user interface for optimizing urban area classification from Landsat data, Master thesis, Technical University of Munich, 104 pp., 2010.

Anas, A., Arnott, R., and Small, K.: Urban Spatial Structure, American Economic Association, J. Econ. Lit., 36(3), 14261464, 1998.

Bartusch, M., Miller, D., and Zink, M.: TanDEM-X Mission Overview and Status, Proceedings of EUSAR 2010, 2010.

Becker, A. and Grünewald, U.: Flood Risk in Central Europe, Science, 300, 5622, p. 1099, 2003.

Brakenridge, G. R., Anderson, E., Nghiem, S. V., Caquard, S., and Shabaneh, T. B.: Flood warnings, flood disaster assessments, and flood hazard reduction: The roles of orbital remote sensing, Proceedings of the 30th International Symposium on Remote Sensing of Environment, Honolulu, Hawaii, USA, 2003.

Brivio, P. A., Colombo, R., Maggi, M., and Tomasoni, R.: Integration of remote sensing data and GIS for accurate mapping of flooded areas, Int. J. Remote Sens., 23, 429-441, 2002.

Domenikiotis, C., Loukas, A., and Dalezios, N. R.: The use of NOAA/AVHRR satellite data for monitoring and assessment of forest fires and floods, Nat. Hazards Earth Syst. Sci., 3, 115-128, doi:10.5194/nhess-3-115-2003, 2003.

Erdik, M.: Earthquake risk assessment for Istanbul Metropolitan area, The American Red Cross - Turkish Red Crescent, Department of Earthquake Engineering, Bogazici University Istanbul, 352 pp., 2002.

Esch, T.: Automatisierte Analyse von Siedlungsflächen auf der Basis höchstauflösender Radardaten, Ph.D. thesis, Bayerische Julius-Maximilian Universität, 202 pp., 2006.

Esch, T., Himmler, V., Schorcht, G., Thiel, M., Wehrmann, T., Bachofer, F., Conrad, C., Schmidt, M., and Dech, S.: Large-area assessment of impervious surface based on integrated analysis of single-date Landsat-7 images and geospatial vector data, Remote Sens. Environ., 113, 1678-1690, 2009.

Fema (Federal Emegrgency Management Agency): HAZUS - Hazards United States, available at: www.fema.gov/plan/ prevent/hazus/ (last access: 16 November 2010), 2007.

Freeman, S. A.: Review of the development of the capacity spectrum method, ISET Journal of Earthquake Technology, Paper No. 438, 41(1), 1-13, 2004.

Hahmann, T., Roth, A., Martinis, S., Twele, A., and Gruber, A.: Automatic Extraction of Water Bodies from TerraSAR-X Data, in: 2008 Boston IEEE International Geoscience and Remote Sensing Symposium (IGARSS), Boston, USA, 6-11 July 2008.

Hofmann, A. D.: An approach to 3D building model reconstruction from airborne laser scanning data using parameter space analysis and fusion of primitives, Ph.D. thesis, Dresden, 115 pp., 2005.

Hoffmann, J., Zebker, H. A., Galloway, D. L., and Amelung, F.: Seasonal subsidence and rebound in Las Vegas, Nevada, observed by synthetic aperture radar interferometry, Water Resour. Res., 37(6), 1551-1566, 2001.

Hoffmeyer-Zlotnik, J. H. P.: Das "Wohnquartier" als Hintergrundmerkmal zur Erklärung von Umfragdaten, edited by: Mohler, P. $\mathrm{Ph}$. and Luettinger, P., Festschrift für Max Kaase, Mannheim: ZUMA, 232 pp., ISBN 3-924220-20-4, 2000 (in German).

Horritt, M. S., Mason, D. C., Cobby, D. M., Davenport, I. J., and Bates, P. D.: Waterline mapping in flooded vegetation from airborne SAR imagery, Remote Sens. Environ., 85, 271-281, 
2003.

Islam, M. and Sado, K.: Development of a flood hazard maps of Bangladesh using NOAA-AVHRR images with GIS, Hydrological Science Journal, 45(3), 337-356, 2000.

Islam, M. M. and Sadu, K.: Flood damage and modeling using satellite remote sensing data with GIS: Case study of Bangladesh, in: Remote Sensing and Hydrology 2000, edited by: Owe, M., Brubaker, K., Ritchie, J., and Rango, A., IAHS Publication, Oxford, 455-458, 2001.

Kass, S., Post, J., Taubenböck, H., Roth, A., Strunz, G., Stötter, J., Mardiatno, D., Ismail, F. A., and Anwar, H. Z.: Automated assessment of building vulnerability with high resolution IKONOS data for Padang, Indonesia, The International Symposium on Disaster in Indonesia: Problems and solutions, Padang, July 2007.

Kron, W.: Flood risk = Hazard $\mathrm{x}$ Exposure $\mathrm{x}$ Vulnerability, Journal of Lake Sciences, 15, sppl., 185-204, 2003.

Leone, F., Denain, J.-C., Vinet, F., and Bachri, S.: Analyse spatiale des dommages au bâti d Banda Aceh (Sumatra, Indonésie): contribution à la connaissance du phénomène et à l'élaboration de scénarios de risque tsunami, in: Le tsunami du 26 décembre 2004 en Indonésie, edited by: Lavigne, F. and Paris, R., Rapport scientifique du programme TSUNARISQUE (20052006), 69-94, Délégation Interministérielle pour l'aide PostTsunami (DIPT), Ambassade de France en Indonésie, Centre National de la Recherche Scientifique, p. 356, 2007.

Marschalk, U., Roth, A., Eineder, M., and Suchandt, S.: Comparison of DEMs derived from SRTM/X- and C-Band, Proceedings of the IGARSS 2004, Anchorage, USA, 2004.

Martinis, S., Twele, A., and Voigt, S.: Towards operational near real-time flood detection using a split-based automatic thresholding procedure on high resolution TerraSAR-X data, Nat. Hazards Earth Syst. Sci., 9, 303-314, doi:10.5194/nhess9-303-2009, 2009.

Mason, D. C., Horrit, M. S., Dall'Amico, J. T., Scott, T. R., and Bates, P. D.: Improving River Flood Extent Delineation From Synthetic Aperture Radar Using Airborne Laser Altimetry, IEEE T. Geosci. Remote, 45, 3932-3943, 2007.

Matgen, P., Schumann, G., Henry, J. B., Hoffmann, L., and Pfister, L.: Integration of SAR-derived river inundation areas, highprecision topographic data and a river flow model toward near real-time flood management, Int. J. Appl. Earth Obs., 9, 247263, 2007.

Meinel, G., Schumacher, U., and Hennersdorf, J.: GIS-Technical Evaluation of the Flood Disaster in Summer 2002 with respect to the City of Dresden on the Basis of Remote Sensing, Laser Scanner and Measurement Data, ISPRS International Archives of the Photogrammetry, Remote Sensing and Spatial Information Sciences, XXXIV, 104-111, 2003.

Mertins, G.: Urbanisierung, Metropolisierung und Megacities. Ursachen der Stadtexplosion in der Dritten Welt, in: Mega-Städte - Zeitbombe mit globalen Folgen?, Deutsche Gesellschaft für die Vereinten Nationen, Bonn, 7-21, 1992 (in German).

Morss, R. E., Wilhelmi, O. V., Downtown, M. W., and Gruntfest, E.: Flood risk, uncertainty, and scientific information for decision making - Lessons from an interdisciplinary project, American Meterological Society, 1593-1601, 2005.

Munich Re Group: TopicsGeo: Natural catastrophes 2008 - Analyses, assessments, positions, available at: http:// www.munichre.com/publications/302-06022_en.pdf (last access 16 November 2010), 2009.

Münich, J., Taubenböck, H., Stempniewski, L., Dech, S., and Roth, A.: Remote sensing and engineering: An interdisciplinary approach to assess vulnerability in urban areas, First European Conference on Earthquake Engineering and Seismology, Geneva, Switzerland, 10 pp., 2006.

Nirupama, N. and Simonovic, S. P.: Increase of Flood Risk due to Urbanisation: A Canadian Example, Nat. Hazards, 40, 25-41, 2007.

Parkinson, C. L. and Greenstone, R.: EOS data products handbook, Volume 2, NASA Goddard Space Flight Center, Greenbelt, Maryland, USA, 2000.

Pesaresi, M., Gerhardinger, A., and Haag, F.: Rapid damage assessment of built-up structures using VHR satellite data in tsunami-affected areas, Int. J. Remote Sens., 28(13-14), 30133036, 2007.

Plate, E. J.: Flood risk and flood management, J. Hydrol., 267(1-2), 2-11, 2002.

Rabus, B., Eineder, M., Roth, A., and Bamler, R.: The Shuttle Radar Topography Mission (SRTM) - A New Class of Digital Elevation Models Acquired by Spaceborne Radar, ISPRS J. Photogramm., 57, 241-262, 2003.

Saito, K., Spence, R., Going, C., and Markus, M.: Using highresolution satellite images for post-earthquake building damage assessment: A study following the 26 January 2001 Gujarat Earthquake, Earthq. Spectra, 20(1), 145-169, 2004.

Sanyal, J. and Lu, X. X.: Application of Remote Sensing in Flood Management with Special Reference to Monsoon Asia: A Review, Nat. Hazards, 33, 283-301, 2004.

Schultz, G. A.: Remote sensing for forecasting of floods (chapter 21) and remote sensing for control of floods (chapter 36), in: Coping with Floods, edited by: Rossi, G., Harmancioglu, N., and Yevjevich, V., Kluwer Academic Publishers, The Netherlands, 459-472, 697-703, 1994.

Schumann, G., Black, A., Cutler, M., Henry, J.-B., Hoffmann, L., Matgen, P., and Pfister, L.: Hydraulic and event knowledge to reduce the positional uncertainty in SAR flood images for improved flood model calibration and development, 7th International Symposium on Spatial Accuracy Assessment in Natural Resources and Environmental Sciences, Lisbon, Portugal, 633-642, 2006.

Shrubsole, D.: The cultures of flood management in Canada: Insights from the 1997 Red River experience, Can. Water Resour. J. 26(4), 461-479, 2001.

Shukla, A.: Environmental Impact Assessment of Flood in the Lower Rapti River Basin, un-published Ph.D. thesis, Department of Geography, Jamia Milia Islamia, New Delhi, India, 2009.

Taubenböck, H., Roth, A., and Dech, S.: Linking structural urban characteristics derived from high resolution satellite data to population distribution, in: Urban and Regional Data Management, edited by: Coors, V., Rumor, M., Fendel, E., and Zlatanova, S., Taylor \& Francis Group, London, 35-45, ISBN 978-0-41544059-2, 2007.

Taubenböck, H., Post, J., Roth, A., Zosseder, K., Strunz, G., and Dech, S.: A conceptual vulnerability and risk framework as outline to identify capabilities of remote sensing, Nat. Hazards Earth Syst. Sci., 8, 409-420, doi:10.5194/nhess-8-409-2008, 2008. 
Taubenböck, H., Roth, A., and Dech, S.: Mega cities: Hints on risk management using EO data, in: Global Mapping of Human Settlements: Experiences, Data Sets, and Prospects, edited by: Gamba, P. and Herold, M., Taylor \& Francis Group, ISBN 9781-4200-8339-2, 205-230, 2009a.

Taubenböck, H., Münich, C., Zschau, J., Roth, A., Dech, S., and Mehl, H.: Assessing building vulnerability using synergistically remote sensing and civil engineering, in: Urban and Regional Data Management, edited by: Krek, A., Rumor, M., Zlatanova, S., and Fendel, E., Taylor \& Francis Group, London, 287-300, ISBN 978-0-415-55642-2, 2009 b.

Taubenböck, H., Wurm, M., Setiadi, N., Gebert, N., Roth, A., Strunz, G., Birkmann, J., and Dech, S.: Integrating Remote Sensing and Social Science - The correlation of urban morphology with socioeconomic parameters, in: Urban Remote Sensing Joint Event, Shanghai, China, 7 pp., 2009c.

Taubenböck, H., Goseberg, N., Setiadi, N., Lmmel, G., Moder, F., Oczipka, M., Klüpfel, H., Wahl, R., Schlurmann, T., Strunz, G., Birkmann, J., Nagel, K., Siegert, F., Lehmann, F., Dech, S., Gress, A., and Klein, R.: "Last-Mile" preparation for a potential disaster - Interdisciplinary approach towards tsunami early warning and an evacuation information system for the coastal city of Padang, Indonesia, Nat. Hazards Earth Syst. Sci., 9, 1509-1528, doi:10.5194/nhess-9-1509-2009, 2009d.

Taubenböck, H., Esch, T., Wurm, M., Roth, A., and Dech, S.: Object-based feature extraction using high spatial resolution satellite data of urban areas, J. Spat. Sci., 55(1), 117-133, 2010.

Thiel, M., Esch, T., and Dech, S.: Object-oriented detection of settlement areas from TerraSAR-X data, in: Proceedings of the EARSeL Joint Workshop: Remote Sensing: New Challenges of high resolution, edited by: Jürgens, C., Bochum, Germany, 242248, ISBN 978-3-925143-79-3, 2008.

Thieken, A. H., Müller, M., Kreibich, H., and Merz, B.: Flood damage and influencing factors: New insights from the August 2002 flood in Germany, Water Resour. Res., 41(12), 1-16, 2005.

Tholey, N., Clandillon, S., and De Fraipont, P.: The contibution of spaceborne SAR and optical data in monitoring flood events: examples in northern and southern France, Hydrol. Process., 11(10), 1409-1413, 1997.

Townsend, P. A. and Walsh, S. J.: Modelling flood plain inundation using integrated GIS with radar and optical remote sensing, Geomorphology, 21(98), 295-312, 1998.
Tralli, D. M., Blom, R. G., Zlotnicki, V., Donnellan, A., and Evans, D. L.: Satellite remote sensing of earthquake, volcano, flood, landslide and coastal inundation hazards, ISPRS J. Photogramm., 59, 185-198, 2005.

UN (United Nations): World Urbanization Prospects - The 2007 revision, New York, 2007.

UN-Habitat: State of the world's cities, available at: http://www.unhabitat.org/documents/media_centre/sowcr2006/ SOWCR\%205.pdf (last access: 16 November 2010), 2007.

UN/ISDR (United Nations/International Strategy for Disaster Reduction): Living with Risk: A Global Review of Disaster Reduction Initiatives, United Nations International Strategy for Disaster Reduction, UN Publications, Geneva, Switzerland, 2004.

Voigt, S., Kemper, T., Riedlinger, T., Kiefl, R., Scholte, K., and Mehl, H.: Satellite image analysis for disaster and crisismanagement support, IEEE T. Geosci. Remote, 45(6), 1520 1528, 2007.

Wang, Y.: Seasonal change in the extent of inundation on floodplains detected by JERS-1 Synthetic Aperture Radar data, Int. J. Remote Sens., 25, 2497-2508, 2004.

Wadge, G., Wislocki, A. P., Pearson, J., and Whittow, J. B.: Mapping natural hazards with spatial modeling system, in: Geographic Information Handling Research and Applications, edited by: Mather, P. M., John Wiley and Sons Inc., New York, 1993.

Wurm, M., Taubenböck, H., Roth, A., and Dech, S.: Urban structuring using multisensoral remote sensing data, in: Proceedings of 2009 Urban Remote Sensing Joint Event, 8 pp., 2009.

Wurm, M., Taubenböck, H., Esch, T., Schardt, M., and Dech, S.: Multisensor Image and Information Fusion for object-oriented mapping of urban objects and spatial structure, International Journal of Image and Data Fusion, in press, 2011.

Zhang, H., Ma, W., and Wang, X.: Rapid urbanization and implications for flood risk management in hinterland of the Pearl River Delta, China: The Foshan study, Sensors, 8(4), 2223-2239, 2008.

Zwenzner, H. and Voigt, S.: Improved estimation of flood parameters by combining space based SAR data with very high resolution digital elevation data, Hydrol. Earth Syst. Sci., 13, 567-576, doi:10.5194/hess-13-567-2009, 2009. 